\title{
The Impact of Tangible and Intangible Innovation Activities on the New Product Objectives in Three Phases of the Innovation Process: Case of the Fish Industry-Morocco
}

\author{
Fatimaezzahra Fouad, Amina Tourabi, Ghizlane Lakhnati \\ Laboratory of Industrial and Computer Engineering, National School of Applied Sciences, Ibn Zohr University, Agadir, Morocco \\ Email: fouad_fati@yahoo.fr, aminatourabi4@gmail.com, lakhnati_ghizlane@yahoo.fr
}

How to cite this paper: Fouad, F., Tourabi, A. and Lakhnati, G. (2017) The Impact of Tangible and Intangible Innovation Activities on the New Product Objectives in Three Phases of the Innovation Process: Case of the Fish Industry-Morocco. Technology and Investment, 8, 11-32.

https://doi.org/10.4236/ti.2017.81002

Received: November 29, 2016

Accepted: January 21, 2017

Published: January 24, 2017

Copyright $\odot 2017$ by authors and Scientific Research Publishing Inc. This work is licensed under the Creative Commons Attribution International License (CC BY 4.0).

http://creativecommons.org/licenses/by/4.0/

\begin{abstract}
In any industry today, the act of innovation becomes a necessity. However, the understanding of innovation remains partial by most major Moroccan food companies, which have poor evaluation of food products. In this context, we have chosen to evaluate the performance of a new product through its degree of improvement in three stages of internal development: design, prototyping and production. Through the results, we first realized that the most important improvements in these three stages are those of time. These improvements are for the most part affected. In this article, we propose to discuss two aspects, namely the innovation process and its objectives, and the innovation activities contributing to the achievement of these objectives.
\end{abstract}

\section{Keywords}

Innovation Process, Product Innovation, New Product Objectives, Food Product Valuation, Innovation Activities

\section{Introduction}

An abundant literature has accumulated on the theme of innovation, which is widely considered as the basis of a competitive economy.

Some empirical studies were focused primarily on analysis models seeking to link the internal and external factors in the effort of innovation, or based on the approach of technological innovation capacity (CIT) and its connection with the performance of the company or innovative product [1].

In this context, studies omit the peculiarities of steps constituting a process of innovation and can bring even richer information that innovation capacities 
cannot provide. On the other hand, there are approaches that are not sufficiently developed approaches by previous studies on innovation as "the innovation process". Given that the process is the structure of the activities and actions an organization undertakes to achieve its objectives [1], this approach represents the totality of innovative activities that address the internal and external objectives of the innovative product in order to understand the behavior of innovative activity [1].

However, our choice of this field of analysis notes the need to address the problem which reflects a rather contradictory situation of the case of the food industry in Morocco.

First, the food industry sector covers a broad classification of economic activities involving several industries. It has more than 2000 companies in late 2011, representing $26 \%$ of total industrial establishments primarily comprising small and medium enterprises (SME). So it has huge development capabilities referring to agricultural and agro-industrial potential of the country [2].

However, the potential in terms of fish wealth and number of processing units in large or small enterprises remains poorly exploited. This generates a low added value of the new product for export.

This low value is usually caused by a gradual or incremental type of innovation with a low level of research and development.

Given this, our problem is to ensure the achievement of performance objectives of an existing innovative product in the company and look for the factors responsible for its performance.

To study this performance, we choose the "process approach" which will be complemented by what we call "innovation activities". By their nature, these activities affect the attainment of the expected performance objectives.

In this paper, we focus on improvements at some stages of the innovation process. This paper presents a theoretical overview that aims to provide answers to questions listed above under an exploratory descriptive aspect.

\section{Conceptual Framework and Assumptions}

According to a study on the impact of product innovation on performance [3], the results showed that there is a U-shaped relationship between product innovation and most key measures profitability. This $U$-shape has identified the positive impact of highly innovative and less innovative products on performance [3].

Therefore, we find that this type of innovation could be very favorable to the commercial performance to the extent that the least innovative products are more familiar, less uncertain, may have greater synergies and therefore have a higher success rate [1].

\subsection{Product Innovation in Moroccan Food Companies}

For several years, the Moroccan food industry was part of a trend towards loss of competitiveness not only in foreign markets but also in the domestic market. 
However, if we focus on the export activity of the country in terms of agroindustrial products, we will be surprised at the gap between the volume of exported products which registers rather high rate, namely $16 \%$ to $17 \%$ of the producing food which is $30 \%$ of total industrial production, and nature in terms of diversification of great decline compared to international competitors [2].

Other hand, we note that Morocco has launched a series of incentives industrial policies, the Emergence Plan launched in 2008. It is one of the major pillars that allow Morocco to better position itself in global trade and to resist facing the rise of Asian countries. The strategy proposes a profound change in the sector through a better use of agricultural resources and a diversified and competitive exportable supply [1].

It is concluded from the above that the IAA suffers from a large gap between the objectives set by the government and the reality that exudes a qualitative weakness in the offer.

Therefore, much of the exported products are of low added value.

In addition to the inability of our manufacturers to innovate in terms of diversification of products and markets, the weakness of the quality of our products, and the relatively high production costs, were decisive in terms of loss of competitiveness external national companies [1].

That said, and as the incremental innovation could make a product more effective than a more innovative product, it is necessary to test whether our food product reflects this assumption.

To this we must compare these factors with the objectives of product innovation. In our case, we chose the approach "Process" as a reference to internal and external objectives of the new product.

\subsection{The Innovation Process}

The measurement approaches mentioned in the literature namely, the approach of Resource-Based View (RBV) and CIT approach have tried to make a clarification on the contribution of resources and capabilities to the performance of the external innovation; mainly business performance.

What was missing in this sense was the consideration of a process that would address the main steps of a product innovation; and that would measure the performance of the internal innovation of the company before moving to the marketing stage. Called "innovation process", this element is an intermediate part between what we would call "resources" or "innovation input indicators" and "output indicators of innovation" [1].

Based on this new approach of the innovation process [4], based its audit process model: the basic processes and process facilitators. The core processes are:

- Identification of new concepts through a generation of concepts;

- Development of the concept chosen a new prototype. At this level, the author speaks of a product innovation;

- Development of innovation through the manufacturing process. At this level, 
the author speaks of an innovation in the manufacturing process;

- Management Technology. Here we talk about the acquisition of technology.

- For process facilitators, we have:

- The deployment of human and financial resources;

- The effective use of the right tools and systems;

- Provide leadership from senior management.

In general, the new product development process includes a set of activities ranging from the idea of innovation to its realization in the form of an innovative product.

Subsequently, Cooper R. G. (2001) [5] proposed a Stage-Gates model of good practice (Figure 1) consists of five main steps and five test stops.

These test cases are also referred to the decision phase dichotomous decision.

Trigger conditions of an operative phase are firstly the end of the previous phase and the decision to continue, on the other.

The utility of the above process lies in the role played by the test phases in the validation of objectives at the end of each of the five main steps.

Therefore, our choice of the process approach comes from two reasons:

- It contains sub-processes that describe the new product development from concept to production;

- It identifies the performance objectives to be achieved through the phases of the test;

- It highlights the elements that contribute to product development in order to facilitate the evaluation of the performance in each of these sub-processes.

Then, in our present study, we will limit ourselves to a dimension of internal measurement at 3 phases, namely: the design, development and production.

These three phases characterize an internal dimension for measuring the performance of an innovative product. The external dimension meanwhile is generally characterized by the commercialization phase.

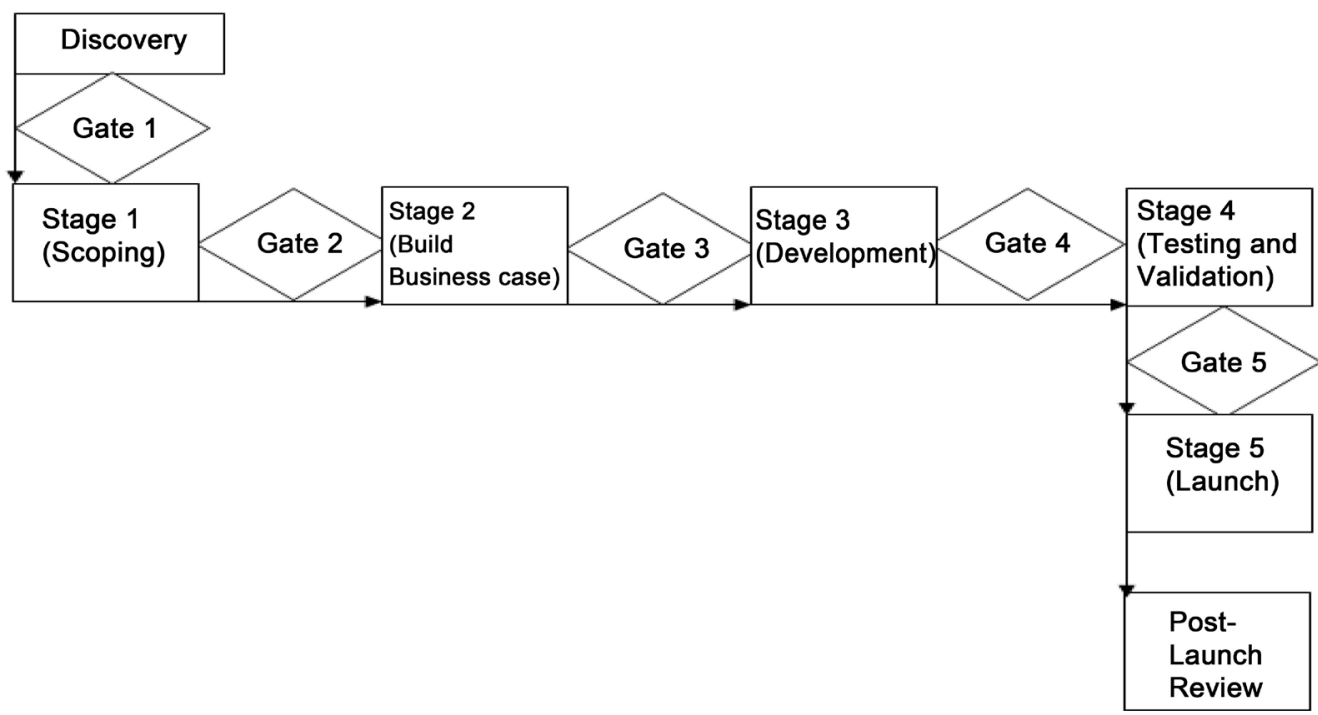

Figure 1. Stage-Gate: A five-stage, five-gate model along with discovery and post-launch (Cooper R. G., 2001) [5]. 
In several studies, the authors (Blindenbach Driessen et al., 2005; Griffin \& Page, 1993) [6] [7] emphasize the external dimension. However the operations management literature emphasizes the use of operational measures that assess the development effort of the internal point of view, such as the time of development or achievement of cost and quality.

As we seek to measure the internal product success in its development process, we must refer to the general objectives sought for a product at the New Product Development (NDP).

Thus at every stage of the innovation process, there are objectives.

Note that in terms of performance measurement, the process reflects three main roles: the role of "Objective", the role of "metric", and the role of "reward".

Those who matter to us in this article are the first two roles.

\subsection{Objectives in the Innovation Process}

In a survey conducted in 2001, the measurement of performance in the Finnish industrial sector, Suomala P. [8] focused on the detection of performance measurement practices and the different facets of performance that these practices belong.

The purpose of the study was mainly to describe what the main product development objectives are.

The study chronicles four main objectives:

- The response to customer needs;

- The quality improvement;

- The shortening of product development;

- Product profitability.

In the same survey, performance measures have been identified as indicators most widely used by businesses.

It appeared that $56.8 \%$ of companies measure product development performance with measures that could be associated with time.

The time category mainly contained the following measures:

- Delay of the product development project;

- Product development punctuality Calendar;

- Calendar of objectives and timetable of achievements;

- The time for the idea to product launch on the market.

For the costs of measures, it was shown that $31.8 \%$ of companies use performance measures associated with product development costs. For example:

- The project budget;

- The costs of the NDP;

- The product development costs.

A kind of measure of customer satisfaction within the extent of product development was practiced by $29.6 \%$ of companies.

The category profitability included typical profitability measures such as return on investments and the net profit of a company. The costs of the supply chain included measures which have focused on the cost of the different parts of 
the supply chain:

- The costs of the direct products;

- The manufacturing costs;

- The costs of warranty.

Innovation measures, on the other hand, were mostly connected with the number of patents and patent applications. In line with the identified objectives, performance measures have been identified, namely:

- Measures relating to quality;

- The capacity of the new technologies.

With these objectives, we will try to measure the product performance within each of the three phases of our process (see Figure 2).

For these goals are achieved, the company will need to release some resources. In our case and since we are talking about product innovation, we will present how innovation activities can contribute to achieving these objectives through hypothesis.

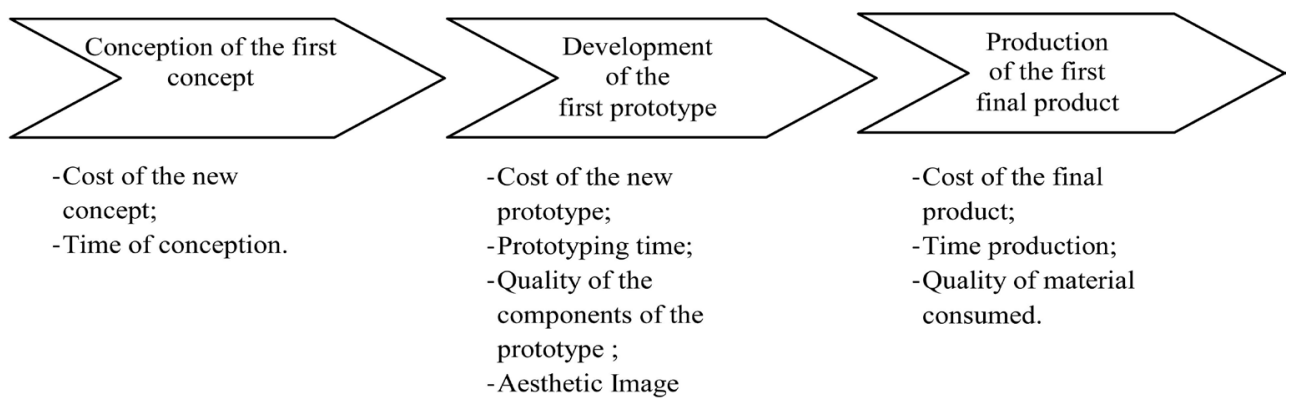

Figure 2. Measurement indicators according to the objectives sought by the company in the 3 phases of development of a new product.

\subsection{Innovation Activities}

In this regard, enterprises should first decide to innovate or not, and if so, how. This is the innovation strategy. Obviously various factors influence this decision. This strategy of innovation itself influenced each other stages of the innovation process.

Once the decision to innovate is made, the company must provide resources. Large companies compared with small companies, have relatively more resources available to conduct innovation activities.

In a study highlighting the effects of the basic factors of innovation on the innovation capacity of manufacturing companies in Malaysia, Suradi N. R. M. [9] identified four generic innovation factors identified by MyTIC2012 for all companies, regardless of their activities. These generally represent the eco-system of the organization and are required for effective implementation of innovation activities, namely:

- Company policy: that is, any form of philosophy, principles, rules, and regulations that must be respected and followed by staff;

- The amount of the budget for the financing of innovation activities, including internal financing and external financing; 
- The number and quality of labor;

- And all the equipment needed to conduct innovative activities, including space and infrastructure, machinery and ICT facilities.

In what follows, we present how innovation activity could influence the goals of a new product in the innovation process.

For this article, we will content ourselves with the last two innovation resources mentioned, namely the number of human resources and tangible and intangible expenditure.

\subsection{The Input in Human Resources}

Among the innovation resources, there are the human resources that can take the form of both tangible and intangible type, there are "men who are human resources distinguishing tangible resources to the extent that they incorporate knowledge and expertise. So men appear as vectors skills of the firm" [10].

Two aspects of the characteristics of the team exist; namely the staff and structure influencing the process of NPD. Power, expertise, and dedication of the team leaders are among the characteristics of staff [11].

Team leaders and members are the people who transform value of ideas, concepts and specifications of new products; thus, they have a central role to facilitate or hinder the process performance, including speed [12].

So we can consider that the team leaders such as engineers, quality responsible and production managers play the largest role in the early stages (see Figure 3 ), i.e. the search for new concepts and their conversion into new products.

Moreover, the structural characteristics reflect how the NPD teams are organized. Differentiation and integration within and between project teams, diversity and functional coordination of balancing teams are among the main factors influencing the performance of NDP [13].

We therefore expect the following hypothesis:

Hypothesis 1: The inputs in Team leaders are significantly and positively related to the performance of the new concept and prototype.

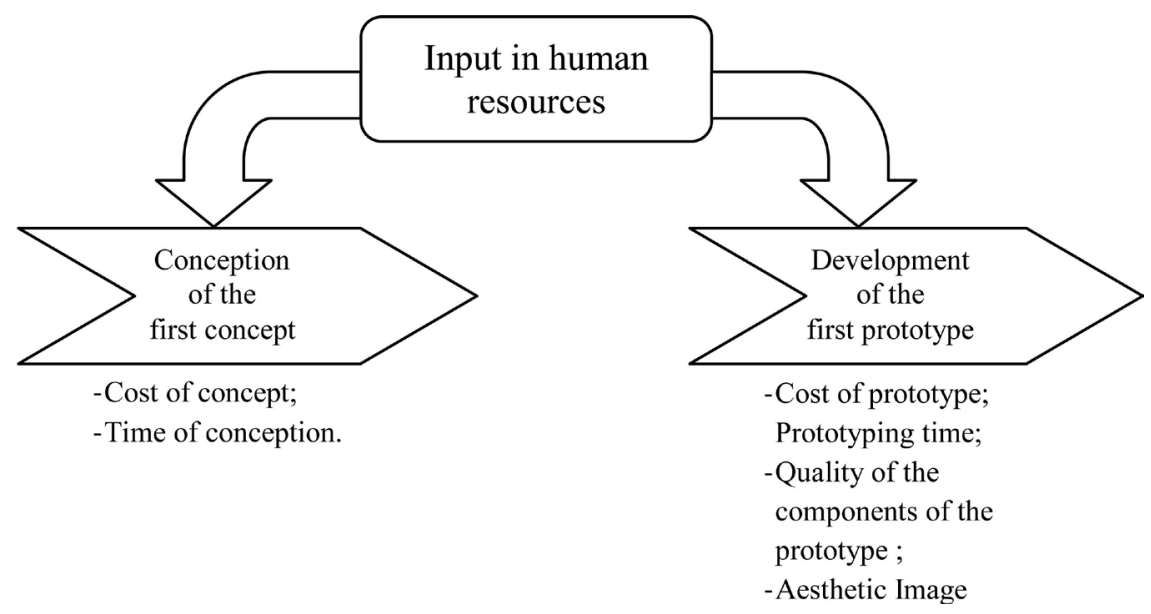

Figure 3. The impact of team leaders on the concept and the prototype development effectiveness. 


\subsection{The Input in Research and Development (R\&D)}

In the context of innovation, "spending on R\&D" was used as an indicator of resources devoted to innovation. A low intensity of $R \& D$, however, is already sufficient for a flow of new products useful in the food industry [14].

A study in Moroccan agribusiness, it was found that during the process product development, the respondents highlighted the importance of the availability of a laboratory in the company to put ideas into practice and perform development testing [15].

This leads us to first locate research and development in the innovation process.

Jefferson G. et al. (2006) [16] found that product innovation is approximately 12 percent return on investment in research and development.

However, other studies [17] have shown that $R \& D$ expenditures do not affect significantly outputs of product innovation. The outputs are represented here by improved prototypes or finished products.

Consequently, and as the food industry does not need a lot of expenditure on $\mathrm{R} \& \mathrm{D}$, we expect that the minimum of these expenditures contribute to the success of the concept and prototype (see Figure 4).

We therefore expect the following hypothesis:

Hypothesis 2: The inputs in $\mathrm{R} \& \mathrm{D}$ are significantly and positively related to the performance of the new concept and prototype.

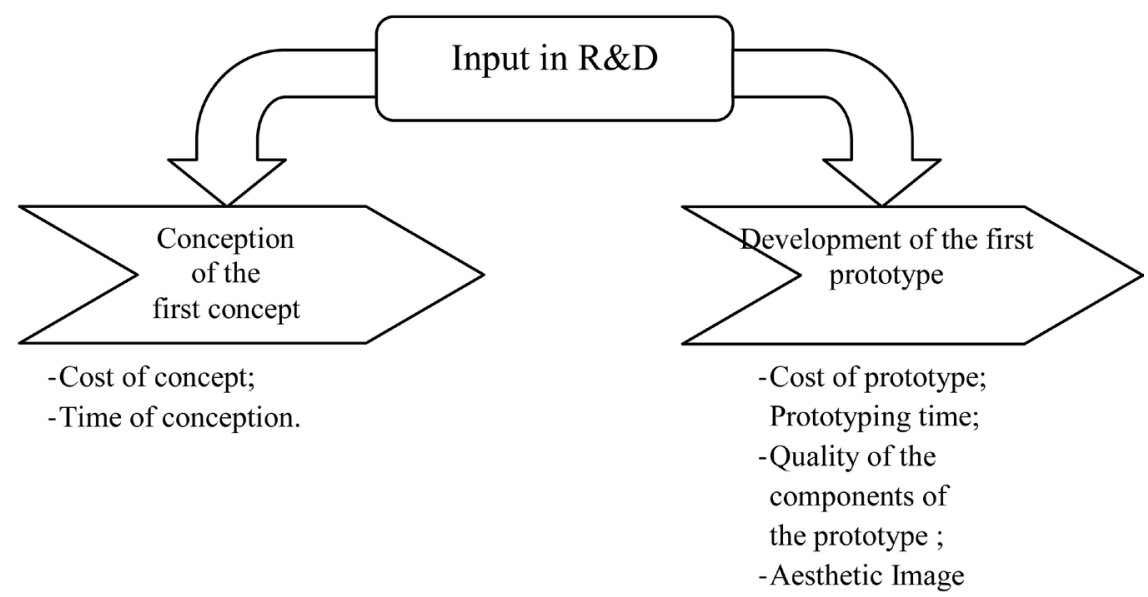

Figure 4. The impact of R\&D on the concept and the prototype development effectiveness.

\subsection{The Input in Tangible and Intangible Investments}

- The input in tangible investments:

These investments cover a range of different business spending in order to generate innovations. In this context, national food enterprises seeking to achieve several objectives, such as increasing production capacity, reducing production time, the extension of the product range, improving product quality and well others. In addition, and given the obstacles plaguing Moroccan IAA in terms of high transportation costs and price volatility of raw materials, the Moroccan 
food industry now faces a major challenge: how to modernize production methods and distribution of the various sectors and how to value agricultural or fish resources for export diversification?

The company wishing to innovate must also devote some of its revenue to invest in technology and infrastructure [18].

According to a study on the seafood sector with major global fishery countries (Norway, Iceland, Denmark, Sweden and Japan), the main factors promoting the development of valuation for the seafood sector were presented. Among them, there was the level of industrialization and enhancement of the sector resulting from commercial dynamism, technological level, and advanced industrialization.

From the nature of these investments, we find that they mainly concern the stages of development and production (see Figure 5).

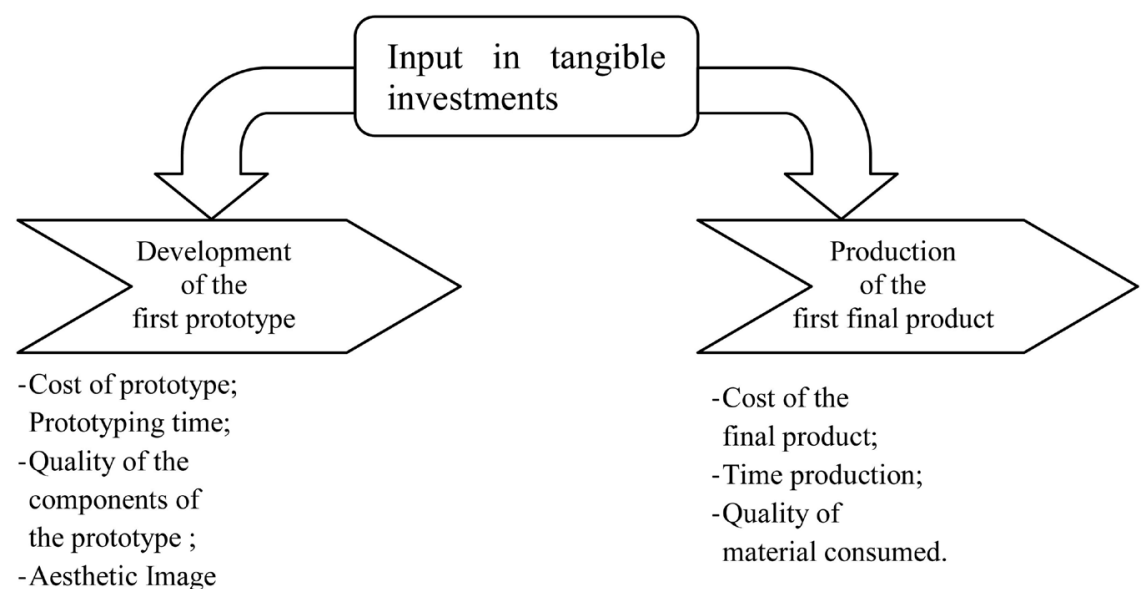

Figure 5. The impact of tangible investments on the prototype development and the final product effectiveness.

Besides this, the company will need technical skills to implement specific and complex machines and systems required for production [18].

We therefore expect the following hypothesis:

Hypothesis 3a: The importance given to material investment is positively associated with the performance of prototype and final product.

- The input in intangible investments:

Previous research suggests that the implementation phase of the original idea generation and screening are of great importance for the success of the new product [19]. The basic assumption behind the knowledge production function (KPF), Romer (1990) [20] suggests that the generation of ideas do not fall from heaven, but from a stock of accumulated knowledge and available.

On the other hand, according to a study measuring the output of innovation in the innovation process; among the inputs from the initial idea, we find the stock of accumulated patents used as a knowledge capital as is the case for the stock of ideas emanating from a previous research and development activity. This knowledge is used here to influence the input in $R \& D$ (Internal expenditure on R\&D personnel and R\&D) [21].

We can mention in this sense, what we call "the citation of patents." The basic 
assumption in the use of this indicator is that there is a positive relationship between the importance of a patent and the extent to which a patent is cited in subsequent patents. This information on previous patents can be traced in each patent application because it is necessary that each patent cited earlier patents having fairly similar or related technical claims. The number of patent citations for a particular patent indicates its importance or impact.

In one of their first small studies, Narin et al. (1987) [22] find that the quality of business research inputs is strongly correlated with the number of patents and patent citations.

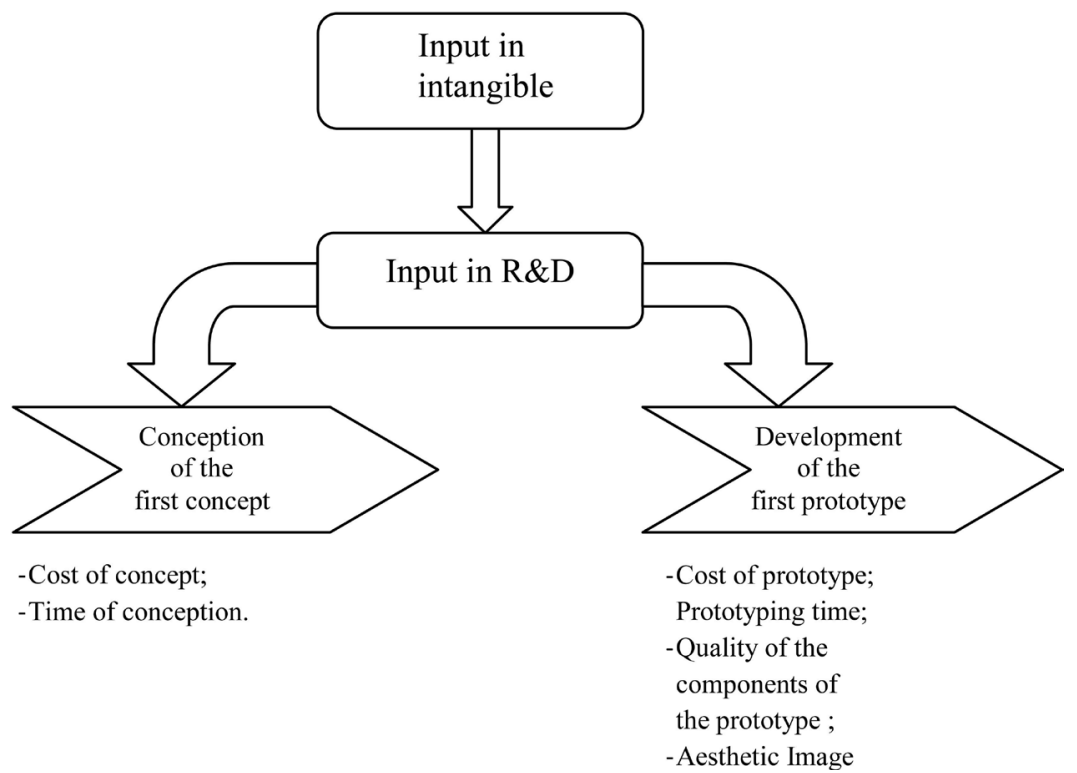

Figure 6. The impact of intangible investments on the concept and the prototype development effectiveness.

Following the study by Chen Kaihua (2011) [17], the results showed that technological innovation accumulation is really able to attract or gather more inputs in $R \& D$ and non-R\&D for technological innovation (see Figure 6). This clearly demonstrates the significant effect of the accumulation of existing technological innovation to attract technological innovation inputs [17].

In this study, we used the patents as an input to the technological and non-technological R\&D.

We therefore expect the following hypothesis:

Hypothesis 3b: Spending on patent acquisitions impact positively and significantly the R\&D input which impact the concept generation and development of the prototype.

With these assumptions, we propose the following model (Figure 7).

\section{Methodology and Measurement Variables}

During our investigation, we encountered several difficulties caused by the extreme confidentiality required by business leaders on the majority of information we wanted. 


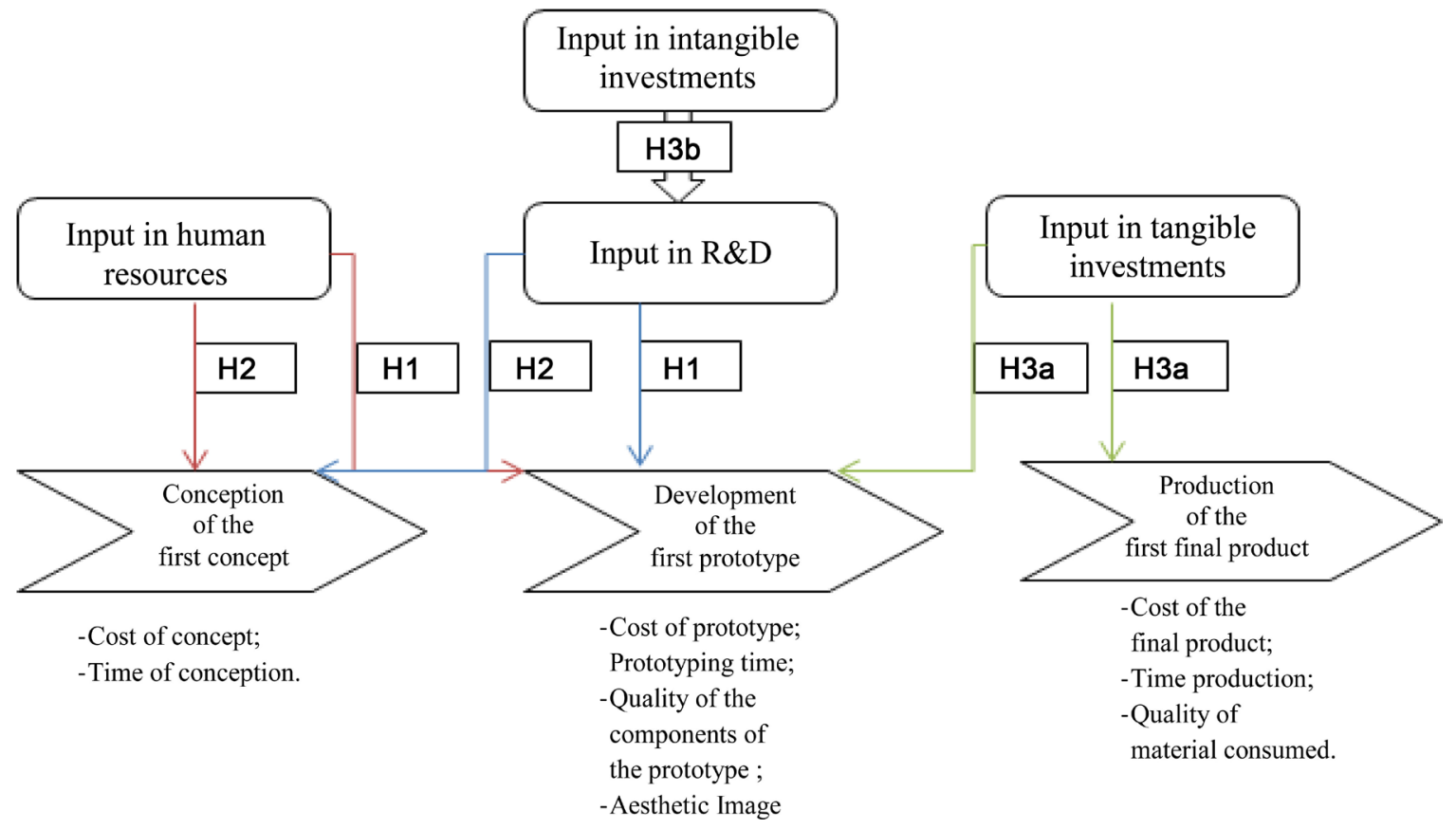

Figure 7. A model offering potential contributions of innovation activities inputs in achieving the objectives of the new product development.

Nevertheless, after six months of field investigation, we could have fairly reliable answers to the 5 companies of 21 major companies operating in the processing of sea products in the Souss-Massa region, representing $24 \%$ of our sample specimen.

\subsection{The Choice of the Sample}

The first step that we have done is to ask the delegation of industry and commerce of the city of Agadir for the list of food companies present in the Souss Massa region.

All enterprises was around 75 companies, mainly included the fish freezing companies.

We have identified 19 companies operating in the processing of products, which represent $25 \%$ of the total, and 56 companies operate in freezing fish, which represent $74 \%$ of the total workforce.

Therefore, we have chosen that our main sample will be based solely on companies operating in the processing of seafood products; since they are more apt to innovate than the manufacturers of frozen products.

We subsequently contacted by telephone all the undertakings concerned by the processing of sea products one by one. This step allowed us first to know the company's location for our future visit and to be able to fix an appointment with one of the managers of product development.

During this first contact, we discarded those of 19 companies that didn't want to meet us or no longer existed.

We also discovered that taking appointments by phone was not working with some companies that responded. It is sometimes found that those responsible 
are absent or busy.

Therefore, we chose to go introduce ourselves to the factory of the company directly without prior appointment.

This direct contact has taken us to know which companies are willing to give their time to conduct the first interview and the companies that are not.

Once the company accepts to deliver some information on its activity, the first question we ask is if it was developing its products or not. If it has already developed or currently developing its product, we give him the interview guide that we will discuss later in this article.

During conducting the interview guide with the company, the manager (manager or head of the quality department) explains the context in which the product was developed within the company by presenting us the various phases through which the new product was developed from the receipt of raw materials to the production or marketing.

In total we were able to contact 3 large companies doing almost the same thing at the fish cannery, which generally represent the same aspects of production that can exist among 16 other companies in our sample.

Via this important step, which lasted one month, we could have an understanding of the field.

In this sample, we calculated the percentage of companies for each type of product, namely: canned goods and semi-preserved products.

Of the 19 fish processing companies, we calculated 13 companies producing canned goods and 6 companies producing semi-preserved.

In Table 1, we present the descriptive data of the 19 enterprises according to the nature of their activity.

From these data, we performed a chi-square adjustment test by which we number canning companies by 1 and the semi-preserved by 2 . The statistics is as follows:

$$
\chi^{2} \text { calculated }=\sum_{j=1}^{J} \frac{(O j-E j)^{2}}{E j}
$$

where

$O_{j}=$ observed frequency;

$E_{j}=$ theoretical frequency;

with

$\mathrm{HO}=$ the two types of companies are not different from one to the another (The observed distribution is consistent with the theoretical law);

$\mathrm{H} 1$ = the two types of companies are different from one to the another (The observed distribution is not consistent with the theoretical law).

We found at the degree of freedom $(2-1=1)$, a value of chi-square $=2.6<$ theoretical chi-square $=3.84$ (see Table 2 ).

Therefore, we accept the null hypothesis.

After completing our questionnaire from the field data, we began administering it to the 19 companies in our sample.

Based on this sample, we found that $74 \%$ of companies were not ready to fill 
Table 1. Descriptive statistics.

\begin{tabular}{ccccccc}
\hline & Statistical characteristics & $\mathrm{N}$ & Mean & SD & Minimum & Maximum \\
Fish Industry's characteristics & 19 & 1.32 & 0.478 & 1 & 2 \\
\hline Activity Type & 19 & 10.79 & 3.343 & 6 & 13 \\
\hline Number of Companies & 19 &
\end{tabular}

Table 2. A chi-square adjustment test.

\begin{tabular}{|c|c|c|c|c|c|c|}
\hline Statistical characteristics & $\begin{array}{l}\text { Observed } \\
\text { number }\end{array}$ & $\begin{array}{c}\text { Theoretical } \\
\text { number }\end{array}$ & Residue & Chi-square & Ddl & $\begin{array}{l}\text { Asymptotic Mean- } \\
\text { ing (signification) }\end{array}$ \\
\hline Canned fish products & 13 & 9.5 & 3.5 & 2.579 & 1 & 0.108 \\
\hline Semi-canned fish products & 6 & 9.5 & -3.5 & & & \\
\hline Total & 19 & & & & & \\
\hline
\end{tabular}

Confidence interval 95\%

Table 3. The characteristics of companies that responded to our questionnaire.

\begin{tabular}{cccc}
\hline & Nature & Number & Percentage \\
\hline \multirow{2}{*}{ Export market } & UE & 5 & $100 \%$ \\
& USA & 3 & $60 \%$ \\
Reason of innovation & Response to market need & 5 & $100 \%$ \\
& Resolution of an internal problem & 0 & $0 \%$ \\
\hline
\end{tabular}

the questionnaire. The cause of this refusal was due largely to a purely stable activity over time with the same product. Others, on the other hand, simply refuse to welcome us on their premises.

Having passed through all these steps, we ended up with five large companies in total which were able to correctly answer our questionnaire. They represent $26 \%$ of the original sample.

Following this, we have identified the following outcomes related businesses:

We see from Table 3, that the most common reason for innovation between the 5 companies is the response to the customer's need.

\subsection{Data and Measures}

As previously announced, the method we have pursued for data collection included three main steps:

- The stage of direct interview during the month of March 2015. An interview guide was sent to the Quality Managers of some companies to which we sent the questionnaire thereafter;

- The stage of the construction of the questionnaire with the answers collected from the interview and recounted indicators in the theory of measurement of innovation. This step was flown between April and May of 2015;

- The stage of distribution of the questionnaire for companies. It began in June 2015 and ended with 5 companies in total end of December of the same year.

This last stage included the correction of the questionnaire in the same time of its administration. 


\subsection{The Interview Guide}

The interview guide was based on one question which was the heart of our research.

We ask the company to tell us what tasks she had undertaken to design and develop its product (see Table 4).

Our goal was to facilitate observation of product objectives expected at the end of each task in the process of development.

This stage of the interview guide also allowed us to become familiar with the practices or main constitutive phases of the development process of a new product in order to formalize them later.

Through this table, we noted that the stages of development and manufacture of new products require intense preparations in the company. These preparations in turn generate costs and delays to assume.

We specify that we stopped at the stage of production because the manufacturing plants of these companies contain no marketing department.

\subsection{The Construction of the Questionnaire}

We tried in the questionnaire to focus on resources and tasks that are related to

Table 4. The tasks pursued in the realization of a new product from concept to production in a fish cannery business.

\begin{tabular}{|c|c|}
\hline The phase & The task \\
\hline $\begin{array}{l}\text { The generation of the first } \\
\text { concept idea }\end{array}$ & $\begin{array}{l}\text { Detection of needs among customers with either a directly or through an evaluation sheet completed by the client; } \\
\text { Meeting with qualified staff to agree on the idea to maintain; } \\
\text { Development of the initial concept. }\end{array}$ \\
\hline $\begin{array}{l}\text { The development } \\
\text { of a new concept }\end{array}$ & $\begin{array}{l}\text { Verification of the manufacturing process so that it can meet the requirements of the new concept } \\
\text { Collaboration with qualified staff to develop the final concept; } \\
\text { Preparation of the final concept. }\end{array}$ \\
\hline $\begin{array}{l}\text { The development of a new } \\
\text { prototype }\end{array}$ & $\begin{array}{l}\text { Verification of the manufacturing process so that it can meet the requirements of the new prototype; } \\
\text { Collaboration with qualified personnel in developing the final prototype; } \\
\text { Make a documented manufacturing test samples of the new product; } \\
\text { Development of a process flow diagram; } \\
\text { Developing a plan for monitoring and control; } \\
\text { Establishment of a risk analysis after a HACCP study of the raw material; } \\
\text { Preparation of the final prototype; } \\
\text { The internal tasting; } \\
\text { The evaluation of ingredients (the required rate, taste, texture) with potential clients; } \\
\text { Launch of the aging test; } \\
\text { Developing a provisional specifications; } \\
\text { Validation of packaging and labeling. }\end{array}$ \\
\hline The production & $\begin{array}{l}\text { Validation rate of the ingredients, the taste, smell and texture of the product (sensory analysis); } \\
\text { The validation of the DLUC and DLC; } \\
\text { Industrialization (procurement of equipment and materials needed to manufacture); } \\
\text { Verification of storage conditions; } \\
\text { The manufacture of pre-production (test samples) to test with customers; } \\
\text { Determining conditions of use; } \\
\text { The final production start; } \\
\text { Correction of detected nonconformity. }\end{array}$ \\
\hline
\end{tabular}


innovation activity only.

In Table 4, the resources and indicators to measure innovation were largely borrowed from the theory. We then supplemented them by indicators specific to the nature of the activity emerged during our interviews with these companies.

The resources and indicators were based on qualitative values (ordinal following a Likert scale).

The resources of the innovation correspond to the inputs of the innovation process, and the indicators relate to outputs based on the objectives achieved in the new product design to final production.

The reference period we have chosen to measure our indicators for this article, was the period in which appeared the first version of innovation in the product in question symbolized by (T-1) (see Table 5).

The performance indicators represented by the objectives of product innovation reflect the improvement of some new product components. In other words, we are simply asking the manager if the objective quality has been improved or not in a given period. We do not care about the efficiency of the indicator in function of the resources allocated.

The inputs and objectives identified in the theory and complemented by the interview guide can be found in Table 5 .

Table 5. The indicators used in measuring the impact of the innovation introduced to an existing product.

10 Innovation activities (the innovation resources) Output measurement indicators (The objectives of product innovation internally)

\author{
Administrative team T-1 \\ Research and development engineers T-1 \\ Workforce T-1 \\ Spending on internal research and development T-1 \\ The development of the new concept \\ Spending on external research and development T-1 \\ The development of the new prototype \\ Spending on software for research and development T-1 \\ Production \\ Spending on information technology T-1 \\ Equipment and material expenses T-1 \\ Spending on advanced technologies T-1
}

In June 2015, we began to administer the questionnaire to companies that may have a seafood processing business and we excluded companies operating in frozen products.

The choice of this segment comes from the idea that the activity of transformation could be more conducive to product innovation activity relative to that of the freezing.

The manager to whom we sent our questionnaire is the quality manager. He provided us with information concerning especially the qualitative aspect of the product. This refers to everything related to its quality, health stability, texture, aesthetic image, etc. 
Second, we contacted the sales manager who helped us complete the section on costs incurred and the results generated with approximate values.

In this work, and in the absence of an adequate sample for the application of a reliable linear regression, we considered a non-parametric test in Section 4.3.

\section{Data Analysis and Results}

\subsection{The Indicators of the New Product in the Stages of the Innovation Process}

The three tables, Table 6, Table 7, and Table 8 , reflect, respectively, the number and percentage of enterprises that have improved the objectives of the new concept, the new prototype and the new final product.

\subsection{The Confirmatory Analysis}

After interviewing the companies in each category, it turned out that five companies were all in disagreement with certain variables. Therefore, we chose to

Table 6. The number and percentage of firms in improving the design goals.

\begin{tabular}{ccc}
\hline Number of improvements & Total improvement & \% of the improvement \\
\hline New Design Improvements & 3 & $60 \%$ \\
Easy to adapt to ingredients & 3 & $60 \%$ \\
Design time & 3 & $60 \%$ \\
Cost design & $30 \%$ \\
\hline
\end{tabular}

Table 7. The number and percentage of firms in improving the prototype development goals.

\begin{tabular}{|c|c|c|c|}
\hline $\begin{array}{ll}\text { Number of improvements } \\
\text { New Prototype Improvements }\end{array}$ & Total improvement & $\%$ of the improvement & $\%$ of the non-improvement \\
\hline Quality of product components & 4 & $80 \%$ & $20 \%$ \\
\hline Taste & 5 & $100 \%$ & $0 \%$ \\
\hline Texture & 4 & $80 \%$ & $20 \%$ \\
\hline Smell & 3 & $60 \%$ & $40 \%$ \\
\hline Aesthetic image & 4 & $80 \%$ & $20 \%$ \\
\hline Development time & 2 & $40 \%$ & $60 \%$ \\
\hline Cost of development & 1 & $20 \%$ & $80 \%$ \\
\hline
\end{tabular}

Table 8. The number and percentage of companies improving production targets.

\begin{tabular}{ccc}
\hline \multicolumn{1}{c}{ Number of improvements } & Total improvement & \% of the improvement \\
New Final Product Improvements & 3 & $60 \%$ \\
The number of products rejected & 5 & $100 \%$ \\
Number of non-compliant products & 5 & $100 \%$ \\
Production time & $50 \%$ & $80 \%$ \\
Production cost & 4 & $20 \%$ \\
\hline
\end{tabular}


eliminate them because their variance was zero.

Eliminating these variables enabled us to keep the variables that give us an acceptable Cronbach alpha of and which prove that can significantly affect the improvement of the new product.

Thus, we identified through the following 2 Built:

- The first built including: engineers in research and development, internal spending on research and development, external expenditure on research and development, spending on information technology, spending on equipment and materials, and spending on technology point ;

- The second building including: Workforce;

We noted that the "patents" indicator does not exist either as an input to the innovation process or as a result of performance. Hence, hypothesis $3 \mathrm{~b}$ cannot be verified in our present study.

Therefore, each element of the construct of the dependent and independent variables will divide into three sub-elements each with values 1 and 0 .

This recoding is done with the aim of transforming the qualitative variables into quantitative variables that will be ready for the correlation test that we will apply later on.

For example, for the design cost of the new prototype which is measured on a Likert scale ranging from 1: low to 3: high; It will take the following values:

- For design cost _1: 1 if the design cost improvement is low, 0 otherwise;

- For design cost_2: 1 if the design cost improvement is average, 0 otherwise;

- For design cost_3: 1 if the design cost improvement is high, 0 otherwise.

We conducted thereafter, purification of the scale of all constructs we have; those entries and those outputs. We ended up with the following results.

According to the confirmatory analysis, we assume that built our variables are one-dimensional (see Table 9). This condition is mandatory as part of a reflexive modeling but not in a formative modeling.

The results of the confirmatory analysis have restored to the resources of innovation the following two constructs:

The performance of the new prototype was divided into:

- Internal R \& D expenditure;

- Workforce.

At the level of improvements made in each of the three phases of the innovation process, we had:

- The improvements made to the new design: easy adaptation to ingredients, improved design time, and improved cost;

- The improvements made to the new prototype: the improvement of the quality of the new prototype, its taste, its odor, its development time and its aesthetic image;

- The improvements made in the new final product: improving the number of discards, improving the number of non-compliant products, and improving the cost of production."

Convergent validity of the measurement model scales is assessed by first ex- 
amining the level and significance of the contribution factor (factor loadings) generated by the PLS algorithm (which are interpreted in the same way that

Table 9. The results of the confirmatory analysis of the constructed inputs and performance indicators.

\begin{tabular}{|c|c|c|c|c|c|}
\hline Factor & Items & $\begin{array}{c}\text { Own } \\
\text { values }\end{array}$ & $\begin{array}{c}\text { Factorial } \\
\text { Contributions } \\
\text { (Cross } \\
\text { loadings })\end{array}$ & $\begin{array}{c}\text { Reliability } \\
\text { index: Rho } \\
\text { Dillon-Goldstein }\end{array}$ & $\begin{array}{l}\text { the average } \\
\text { variance } \\
\text { extracted } \\
\text { (AVE) }\end{array}$ \\
\hline R\&D Input & Internal Spending in R\&D & & 1.0000 & & \\
\hline \multirow[t]{2}{*}{ Human resources Input } & Workforce & & 1.0000 & & \\
\hline & Easy adaptation to ingredients (T-1)_2 & 0.4658 & 0.8290 & 0.8858 & 0.7077 \\
\hline \multirow[t]{4}{*}{ New design improvements } & Design time improvement (T-1)_3 & 0.1138 & 0.7513 & & \\
\hline & Cost design improvement (T-1)_1 & 0.0604 & 0.9335 & & \\
\hline & Prototype quality improvement (T-1)_3 & 0.8892 & 0.8773 & 0.9479 & 0.7518 \\
\hline & Prototype tasteimprovement (T-1)_2 & 0.1656 & 0.9403 & & \\
\hline \multirow[t]{4}{*}{$\begin{array}{l}\text { New prototype } \\
\text { improvements }\end{array}$} & Prototype smell improvement (T-1)_2 & 0.0652 & 0.9403 & & \\
\hline & Prototyping time improvement (T-1)_2 & 0.0000 & 0.5805 & & \\
\hline & Prototype aesthetic improvement (T-1)_2 & 0.0000 & 0.9403 & & \\
\hline & Improvement of rejected products number (T-1)_3 & 0.4000 & 0.8868 & 0.8824 & 0.7291 \\
\hline \multirow[t]{2}{*}{$\begin{array}{l}\text { New product } \\
\text { improvements }\end{array}$} & Improvement of non-compliant products number $(\mathrm{T}-1) \_3$ & 0.1600 & 0.8868 & & \\
\hline & Production cost improvement (T-1)_2 & 0.0000 & 0.7839 & & \\
\hline
\end{tabular}

$\mathrm{ACP})$. The usual rules used in the factor analysis for structural equation models, contributions should be high (>0.5) and significant [23].

The convergent construct validity can also be evaluated by showing that the items measuring a built are more highly correlated with the construct with the other built the model [24].

Here, we find that the absolute contributions of variables 8 built are all above 0.5 (see Table 9).

From the table above, the average variance extracted (Average Variance Extracted" or AVE) also called average community is greater than the variance shared between the built and the other constructs of the model (the squared correlation between two built) [25]. This shows that constructs are discriminated against (see Table 9).

\subsection{The Correlation Test between Innovation Resources and the Process Input Indicators}

Since we recoded our variables (explanatory and explained) so that they become quantitative, we chose to apply a Pearson correlation test to detect the nature of the relationship between these two variables.

We remind our assumptions:

Hypothesis 1: The inputs in Team leaders are significantly and positively related to the improvement of the new concept and prototype; 
Hypothesis 2: The inputs in $R \& D$ are significantly and positively related to the improvement of the new concept and prototype;

Hypothesis 3a: The importance given to material investment is positively associated with the improvement of prototype and final product.

We note that a weak improvement in design cost is positively associated but not significantly to the workforce $(r=0.77 ; \mathrm{p}=0.11)$. Nevertheless, this improvement is positively and significantly associated to the spending on IT $(r=$ $0.87 ; \mathrm{p}=0.05$ ). We conclude that the assumptions \#1 and \#2 are enabled for input in personnel and spending on information technology (see Table 10).

What most affects the moderate improvement, are the following inputs: external spending on research and development $(r=0.87 ; p=0.05)$, spending on equipment $(\mathrm{r}=0.87 ; \mathrm{p}=0.04)$, spending on advanced technologies $(\mathrm{r}=0.87 ; \mathrm{p}=$ $0.05)$, and spending on information technology $(r=0.91 ; p=0.02)$. The average improvement of taste is associated with these inputs positively and significantly (see Table 11).

We conclude that the improvement of taste at the new prototype is influenced largely by the first built of research and development factors and the third built of the information technology factor.

From these results, we can confirm the two hypotheses \#1 and \#2 for inputs in $\mathrm{R} \& \mathrm{D}$ and inputs of equipment and materials included spending on information technology.

We notice that a small improvement in time is associated positively but not significantly enough to the number of engineers in research and development $(\mathrm{r}$ $=0.76 ; \mathrm{p}=0.13)$, external spending on research and development $(\mathrm{r}=0.61 ; \mathrm{p}=$ 0.27 ), and spending on advanced technologies $(r=0.62 ; p=0.26)$ (see Table 12).

So we come back to validate both hypothesis \# 1 and \# 2 for inputs in R \& D personnel and expenditures in R\&D.

Here we have the workforce $(r=0.77 ; p=0.11)$, and spending on information technology $(r=0.87 ; \mathrm{p}=0.05)$ which play a role in improving low and moderately the non-compliance of the new final product.

After we have external expenditure on research and development $(r=0.87 ; p$

Table 10. The relationship between expenditure and human resources inputs and improvement of the new design improvements.

\begin{tabular}{cccc}
\hline New design improvements & $\begin{array}{c}\text { Easy adaptation to } \\
\text { ingredients (T-1)_2 }\end{array}$ & $\begin{array}{c}\text { Design time improvement } \\
\text { (T-1)_3 }\end{array}$ & Cost design improvement (T-1)_1 \\
\hline Internal Spending in R\&D & -0.5857 & -0.2689 & -0.3506 \\
\hline
\end{tabular}

Table 11. The relationship between expenditure and human resources inputs and objectives of the new prototype improvements.

\begin{tabular}{|c|c|c|c|c|c|}
\hline Innovation resources & $\begin{array}{l}\text { Prototype quality } \\
\text { improvement } \\
(\mathrm{T}-1) \_3\end{array}$ & $\begin{array}{l}\text { Prototype } \\
\text { tasteimprovement } \\
(\mathrm{T}-1) \_2\end{array}$ & $\begin{array}{l}\text { Prototype smell } \\
\text { improvement } \\
(\mathrm{T}-1) \_2\end{array}$ & $\begin{array}{l}\text { Prototyping time } \\
\text { improvement } \\
(\mathrm{T}-1) \_2\end{array}$ & $\begin{array}{l}\text { Prototype aesthetic } \\
\text { improvement } \\
(\mathrm{T}-1) \_2\end{array}$ \\
\hline Internal Spending in $\mathrm{R} \& \mathrm{D}$ & -0.3506 & 0.4624 & 0.4624 & -0.1605 & 0.4624 \\
\hline Workforce & 0.7799 & 0.1950 & 0.1950 & 0.7164 & 0.1950 \\
\hline
\end{tabular}


Table 12. The relationship between expenditure and human resources inputs and objectives of the new product improvements.

\begin{tabular}{cccc}
\hline New product improvements & $\begin{array}{c}\text { Improvement of rejected } \\
\text { products number (T-1)_3 }\end{array}$ & $\begin{array}{c}\text { Improvement of non-compliant } \\
\text { products number (T-1)_3 }\end{array}$ & $\begin{array}{c}\text { Production cost } \\
\text { improvement (T-1)_2 }\end{array}$ \\
\hline Workforce & 0.2388 & 0.2388 & 0.8969 \\
\hline
\end{tabular}

$=0.05)$ spending on equipment $(\mathrm{r}=0.87 ; \mathrm{p}=0.04)$ spending on advanced technologies $(r=0.87 ; \mathrm{p}=0.05)$ and spending on information technology $(\mathrm{r}=0.91 ; \mathrm{p}$ $=0.02$ ), which affect strongly and significantly enough the low and medium improved time of production.

So we come back to validate the hypothesis $3 \mathrm{a}$ for entries in equipment and materials.

Here we have the engineers in research and development $(r=0.80 ; p=0.10)$ and labor $(\mathrm{r}=0,071 ; \mathrm{p}=0.17)$ associated positively and significantly enough to the average improvement cost of production.

We also return to validate assumptions \#1 and \#2 for inputs in R\&D personnel and workforce.

\section{Discussion and Conclusion}

We have tried through this work to explore a new aspect of the innovationproduct performance. This aspect stems from the objectives of pure and simple improvement of a new product at the stage of development within the company.

This method of measurement has not been sufficiently developed in previous studies. Formerly, the authors focus on the impact of good practices on business performance, which remains external to the company.

However, authors like Griffin and Page have been the typical example that takes into account in their measure of performance only the commercial perspective. However, the Loch et al. [26] Model recognizes the importance of managing processes leading to exit from development, and is used to achieve the success of firms in their market.

Like this, the operational management literature emphasizes the use of operational measures to assess the development effort from the internal point of view, such as development time or the achievement of cost objectives.

Chiou et al. (1999) [27] proposed a model of productivity-based modeling technology-based model called the "TOPMM". The “TOPMM" takes into account all the results of the innovation process: the new final product and the intermediate results (prototypes, models and competences).

On the other hand, we have focused on unfamiliar resources in the world of industry, namely, resources directly related to the innovation activity.

The resources or determinants chosen in this study were selected on the basis of the nature of the stages of the innovation process.

According to the previous studies [9], investments in R\&D and ICT are mainly associated with design and prototyping phases.

This has been effectively validated for the first two stages of the innovation 
process. However, for the production stage, the performance of the new product was rather impacted by the workforce. This is very logical to the extent that the workforce has been well framed by the team leaders.

However, to complement the performance measure of the new product, our internal schema must be linked to an external schema where other measures are taken at post-launching stages.

In addition, internal performance is not simply a matter of improving the cost or quality objective, but concerned with achieving efficiency in the new product.

\section{References}

[1] Fouad, F., Tourabi, A. and Lakhnati, G. (2015) Measuring Innovation in the Process Approach: The Case of Agro-Food Products in Morocco. International Journal of Engineering Research and Applications, 5, 6-11.

[2] EuroMed@Change (2013) Opportunités d'affaires en méditerranée: Focus sur l'Agroalimentaire au Maroc.

[3] Kleinschmidt, E.J. and Cooper, R.G. (1991) The Impact of Product Innovativeness on Performance. Journal of Product Innovation Management, 8, 240-251. https://doi.org/10.1016/0737-6782(91)90046-2

[4] Chiesa, V. and Frattini, F. (1996) Evaluation and Performance Measurement of Research and Development. Journal of Product Innovation Management, 13, 105-136. https://doi.org/10.1016/0737-6782(95)00109-3

[5] Cooper, R.G. (2001) Winning at New Products: Accelerating the Process from Idea to Launch. 3rd Edition, Perseus Books, Reading.

[6] Blindenbach-Driessen, F.P., Van Dalen, J. and Van Den Ende, J. (2005) A Critical Assessment of Performance Measurement of NPD Project. Proceedings of the 12 th International Product Development Management Conference, Copenhagen, 12-14 June 2005.

[7] Griffin, A. and Page, A.L. (1993) An Interim Report on Measuring Product Development Success and Failure. Journal of Product Innovation Management, 10, 291 308. https://doi.org/10.1016/0737-6782(93)90072-X

[8] Suomala, P. (2001) Multifaceted New Product Development Performance: Survey on Utilization of Performance Measures in Finnish Industry. Tampere University of Technology, Cost Management Center on Finland, 1-27.

[9] Suradi, N.R.M., Omar, A. and Shahabuddin, F.A. (2015) The Importance of Basic Factors in Innovation Processes and Their Effects on Innovation Capability of Malaysian-Owned Manufacturing Companies. 2nd ISM International Statistical Conference, Pahang, 12-14 August 2014, 524-530. https://doi.org/10.1063/1.4907489

[10] Lebars, A. (2001) Innovation Sans Recherche: Les compétences pour innover dans les PME de l'agroalimentaire, Thèse, Université Pierre Mendès-France, Grenoble.

[11] Kessler, E.H. and Chakrabarti, A.K. (1996) Innovation Speed: A Conceptual Model of Context, Antecedents and Outcomes. Academy Management Journal, 21, 1143 1191.

[12] Brown, S.L. and Eisenhardt, K.M. (1995) Product Development: Past Research, Present Findings, and Future Directions. Academy of Management Review, 20, 343378.

[13] Adler, P.S. (1995) Interdepartmental Interdependence and Coordination: The Case of the Design/Manufacturing Interface. Organization Science, 6, 147-167. https://doi.org/10.1287/orsc.6.2.147 
[14] Avermaetea, T., Viaenea, J., Morgan, E.J., Crawford, E.P.N. and Mahon, D. (2004) Determinants of Product and Process Innovation in Small Food Manufacturing Firms. Trends in Food Science \& Technology, 15, 474-483. https://doi.org/10.1016/j.tifs.2004.04.005

[15] Hamzaoui, A. and Bouami, D. (2012) Development of an Integrated Innovation Management Methodology Based on Moroccan Agro-Food Firms. International Conference on Education and Management Innovation, 30, 106-110.

[16] Jefferson, G., Bai, H., Guan, X. and Yu, X. (2006) R\&D Performance in Chinese Industry. Economics of Innovation and New Technology, 15, 345-366. https://doi.org/10.1080/10438590500512851

[17] Chen, K. and Guan, J. (2011) Mapping the Innovation Production Process from Accumulative Advantage to Economic Outcomes: A Path Modeling Approach. Technovation, 31, 336-346. https://doi.org/10.1016/j.technovation.2011.03.004

[18] National Federation of Seefood Processing and Valorisation Industries. http://www.fenip.com/fenip/contenu.asp?id_rub=13\&ID_SRUB=23

[19] Cooper, R.G. (1988) The New Product Process: A Decision Guide for Management. Journal of Marketing Management, 3, 238-255.

https://doi.org/10.1080/0267257X.1988.9964044

[20] Romer, P. (1990) Endogenous Technological Change. Journal of Political Economy, 98, 71-102. https://doi.org/10.1086/261725

[21] Guan, J. and Chen, K. (2011) Measuring the Innovation Production Process: A Cross-Region Empirical Study of China's High-Tech Innovations. Technovation, 30, 348-358. https://doi.org/10.1016/j.technovation.2010.02.001

[22] Narin, F., Noma, E. and Perry, R. (1987) Patents as Indicators of Corporate Technological Strength. Research Policy, 16, 143-155. https://doi.org/10.1016/0048-7333(87)90028-X

[23] Roussel, P., Durrieu, F., Campoy, E. and El Akremi, A. (2002) Méthodes d'équations structurelles: Recherches et applications en gestion. Edition Economica, Paris.

[24] Lahmouz, K. and Duyck, J.P. (2008) Implication organisationnelle et stress professionnel, rôle de l'auto-efficacité. Communication au 29ème congrès de I AGRH, Dakar.

[25] Sosik, J., Kahai, S. and Piovoso, M. (2009) Silver Bullet or Voodoo Statistics? A Primer for Using the Partial Least Squares Data Analytic Technique in Group and Organization Research. Group \& Organization Management, 34, 5-36. https://doi.org/10.1177/1059601108329198

[26] Loch, C.H. and Terwiesch, C. (1999) Accelerating the Process of Engineering Change Orders: Capacity and Congestion Effects. Journal of Product Innovation Management, 16, 145-159. https://doi.org/10.1016/S0737-6782(98)00042-3

[27] Chiou, W.C., Kuo, H.W. and Iuan Yuan, L. (1999) A Technology Oriented Productivity Measurement Model. International Journal of Production Economics, 60, 69-77. https://doi.org/10.1016/S0925-5273(98)00187-X 
Submit or recommend next manuscript to SCIRP and we will provide best service for you:

Accepting pre-submission inquiries through Email, Facebook, LinkedIn, Twitter, etc. A wide selection of journals (inclusive of 9 subjects, more than 200 journals)

Providing 24-hour high-quality service

User-friendly online submission system

Fair and swift peer-review system

Efficient typesetting and proofreading procedure

Display of the result of downloads and visits, as well as the number of cited articles Maximum dissemination of your research work

Submit your manuscript at: http://papersubmission.scirp.org/

Or contact ti@scirp.org 